эхоический повтор. Ирония, основанная на противопоставлении идей, может быть подразделена на два подтипа: иронию, основанную на изменении семантического значения неправдивого лексического элемента (одного!) в высказывании, либо изменении прагматического значения всего высказывания. В заключении хотелось бы отметить, что назначением всех указанных типов иронии является выражение насмешливого отношения персонажа к словам собеседника как способа оценки: имплицитного порицания, несогласия, сомнения или недоверия к словам собеседника.

1. Christie, A. The Case of the Discontented Husband Избранные рассказы. Сборник. На англ. яз. / Составитель Н.А Самуэльян. - М.: Издательство «Менеджер», 2004. - c. 254-271

2. Christie, A. The Case of the Rich Woman: An Agatha Christie Short Story, Harper Collins Publishers 2014. - pp. 5-23

3. Dynel, M., 2013. Irony from a neo-Gricean perspective: On untruthfulness and evaluative implicature. Intercultural pragmatics, 10(3), pp.403-431.

4. Grice, H. P. 1975. Logic and conversation. In P. Cole \& J. L. Morgan (Eds.), Speech acts (Vol. 3, pp. 4158). New York: Academic.

5. Henry, O. No Story Избранные рассказы. 5-е изд. - На англ. яз. / Составитель Н.А Самуэльян. - М.: Издательство «Менеджер», 2005. - с. 131-142

6. Maugham, W.S. A Marriage of Convenience. 65 Short Stories by W. Somerset Maugham, 1976, William Heinemann Limited and Octopus Books Limited, pp 253-260

7. Maugham, W.S. Mr Harrington's Washing. 65 Short Stories by W. Somerset Maugham, 1976, William Heinemann Limited and Octopus Books Limited, pp 261-270

8. Wilson D., Sperber D. On Verbal Irony // Irony in Language and Thought. A Cognitive Science Reader. Ed. By H.L. Colston and R.W. Gibbs. - New York, London: Lawrence Erlbaum Associates. 2007. - P. $35-57$.

\title{
Ревеко Л.С. \\ Влияние синтаксических отношений на семантические сдвиги в предложении (на материале немецкого языка)
}

Брянский государственный технический университет

(Россия, Брянск)

doi: 10.18411/lj-05-2021-279

\section{Аннотация}

В статье анализируются отношения между значением грамматических форм и лексическим значением слов. Выявляется степень корреляции лексического и грамматического значения. Рассматривается грамматическое отношение между подлежащим и сказуемым на синтаксическом уровне.

Ключевые слова: грамматическое значение, семантическая структура, номинализация, метафорический сдвиг, глагольная метафора.

\section{Abstract}

The paper analyzes the relationship between the meaning of grammatical forms and lexical meaning of words. The degree of correlation between the lexical and grammatical meanings is revealed. The grammatical relationship between the subject and the predicate at the syntactic level is considered.

Key words: grammatical meaning, semantic structure, nominalization, metaphoric shift, verbal metaphor.

Отношение между значением грамматических форм и лексическим значением слов привлекает внимание многих лингвистов.

Одни направления семантики отрицают любое грамматическое значение и постулируют, прежде всего, нейтралитет синтаксиса по отношению к лексическому 
значению. По их мнению, синтаксические структуры - это чисто формальные несемантизированные схемы предложения, способные наполняться любым лексическим содержанием.

Сторонники противоположной точки зрения исходят из тезиса о том, что смысл слов и функции грамматических форм являются в равной степени вариантами значений.

По мнению С.Д. Кацнельсона [3, с 112-113] обе точки зрения односторонни и несовершенны. Он считает, что было бы неправильно полагать, что грамматические формы не имеют значения как и то, что все грамматические формы семантически наполнены.

В связи с этим возникает вопрос, насколько близко лексическое и грамматическое значения коррелируют между собой.

Цель данной статьи - исследовать проблему корреляции лексического и грамматического значения на основе предложений, в которых существительные в качестве подлежащего обозначают процесс и состояние.

1. Ein Lächeln huschte über sein Gesicht.

2. Ein blindes Hassgefühl schwoll in ihm auf.

Предложения данного вида означают противоречие между единицами семантической и единицами синтаксической структуры. Грамматическое подлежащее не соответствует семантическому подлежащему и не имеет при этом функции агенса. Подлежащее в грамматической структуре предложения проявляет соответствие в семантической структуре, т.е. в пропозиции, в ядре, в семантическом сказуемом. Переходный глагол служит, с одной стороны, для уточнения семантического сказуемого, с другой стороны, он выполняет чисто грамматическую функцию: преобразует пропозицию в предложение.

Такую асимметрию и такое противоречие можно объяснить номинализацией понятий процесса и состояния; сюда же включается и понятие свойства. При субстантивации значение глагола или прилагательного опредмечивается. Предметность - это грамматическое свойство существительного, его категориальное значение, которое выражают субстантивированные глаголы и прилагательные. На грамматический характер опредмечивания указывали еще А. А. Потебня, А. М. Пешковский, В. Порциг и т.д. Согласно А. А. Потебни языковая абстракция - «это особый вид представления» процесса или свойства в языке. Ее смысл состоит в том, что процесс или свойство мыслятся при этом как самостоятельные и могут появляться в функции подлежащего или члена предложения.

Решающим для расширения содержания обсуждаемых структур предложения является грамматическое отношение между подлежащим и сказуемым на синтаксическом уровне, на котором сказуемое характеризует подлежащее. Функция подлежащего - носителя процесса, состояния, свойства - остается та же самая, независимо от лексического значения существительного. Глагол реализует свое значение применительно к значению существительного и подвергается его влиянию. В случае, если подлежащее выражено понятием процесса или состояния, то в значении переходного глагола актуализируются акциональные семы. Семантическое преимущество подлежащего объясняется его коммуникативно-грамматической первостепенной ролью. При этом признаками, характеризующими процессы или состояния, принято считать фазы их протекания, их возникновение или исчезновение, их длительность и интенсивность. Наряду с глаголами, обозначающими фазы интенсивности понятий процесса или состояния, такими, как entstehen, beginnen, verlaufen, losbrechen, sich wiederholen, sich verstärken, sich abschwächen и др., часто в обсуждаемых структурах предложения применяются также глаголы, которые характеризуют, прежде всего, подлежащие с конкретным значением, например: gleiten, ziehen, überfallen, rieseln, sich bemächtigen и др. Значение таких глаголов в сочетании с 
абстрактным существительным регулярно претерпевает метафорические сдвиги. Такая регулярная метафоризация значения глагола характерна для обсуждаемых структур предложения и определяет их своеобразие.

Специфичность семантических свойств глагольной метафоры обусловливается синтаксическими и семантическими характеристиками глагола. Многообразие синтаксических свойств глагола, его конструктивная организующая роль в построении высказывания предопределяют более емкую и гибкую семантическую структуру данной части речи по сравнению с другими лексико-грамматическими разрядами слов [2, С. 339, 341]. По мнению Н.Д. Арутюновой «семантика глагола способна в принципе охватить те типы значения, которые соответствуют зависимым от него синтаксическим местам» $[1$, С. 253].

Чем больше валентность того или иного глагола, тем значительнее его конструктивная роль в организации высказывания, тем сильнее влияние семантики глагола на семантику всех остальных компонентов высказывания. Подобно другим видам метафор глагольная метафора базируется на нарушении лексико-семантической сочетаемости, однако в нее вовлекается не только объект метафоры, но также и другие компоненты высказывания, прямо или косвенно зависимые от глагола. Процесс метафоризации в глагольной метафоре состоит в динамичной характеристике объекта метафоры путем приписывания несвойственных ему воздействующих свойств и качеств, возведения его в ранг активного, конструктивного начала.

Глагол предопределяет не только минимальное количество актантов, обеспечивающее относительную структурную и семантическую завершенность высказывания, но и семантику этих актантов. «Сфера влияния» глагола в предложении распространяется как на обязательные (с точки зрения структурной и семантической завершенности предложения) компоненты, так и на его факультативные компоненты. Ведь характер глагольного действия, семантика глагола тесно связаны с семантикой компонентов предложения, обозначающих орудие действия, место действия, причину действия и т.д. Многообразие и глубина семантических и синтаксических связей глагола в предложении создают благоприятные предпосылки и открывают широкие возможности для процессов метафоризации в тексте.

Метафорические значения глагола особенно разнообразно варьируются при представлении человеческих эмоций. Следующие предложения иллюстрируют данное положение на примере процесса "Lächeln".

1. Über das wetterharte Gesicht des Alten glitt ein Lächeln.

3. Ein Lächeln huschte über sein Gesicht.

4. Zum ersten Mal zieht etwas wie ein Lächeln über sein Gesicht.

5. Auf sein müdes Gesicht stahl sich ein Lächeln.

6. Frankas Lächeln verstärkte sich.

7. Sein Lächeln erlosch.

8. Ein zuckersüßes Lächeln gefror auf ihrem Gesicht.

Содержательную структуру таких предложений отличает постоянная экспликация агенса, выраженного личным местоимением или существительным в родительном падеже. Такое свойство объясняет статус обязательного актанта, содержащего определение места.

В последующих предложениях-примерах метафорические глаголы характеризуют существительные, обозначающие эмоциональные состояния в зависимости от длительности, интенсивности или фазы.

1. Ihn beschlich das Gefühl, eine bereits erlebte Situation wiederholte sich.

2. Jetzt bemächtigte sich ihrer eine seltsame Erregung.

3. Ihn beherrschte ein unangenehmes Gefühl.

4. Ein zärtliches Gefühl durchzog sie.

5. Eine wohlige Schwäche durchrieselte sie. 
6. Abermals durchströmte sie heiße Freude.

7. In Baltrok flammte Hoffnung auf.

9. Ein blindes Hassgefühl schwoll in ihm auf.

Метафорически измененное значение глагола получает новые возможности выражения для характеристики абстрактности. Фаза, длительность, интенсивность могут выражаться глаголом одновременно. Например: beschlich (1) - фаза возникновения (начала), не интенсивно; beherrschte (3) - длительно, интенсивно. Глаголы durchziehen (4), durchrieseln (5), durchströmen (6) означают состояния по их длительности и интенсивности. Приставка durch - способствует переходности глагола, прямое дополнение обозначает лицо, которое различным образом воспринимает состояние. Таким образом, с помощью метафорически изменяемого значения глагола состояние может быть представлено как процесс в своем протекании.

Метафоризацию значения глагола, вызванную абстрактным существительным, можно наблюдать не только в немецком языке, но и в других языках, например, в русском: радость вспыхнула (es brach Freude aus), надежда погасла (jegliche Hoffnung erstarb), улыбка заиграла (ein Lächeln spielte auf ihrem/seinem Gesicht), страх пронзил (sie/ihn durchfuhr ein Entsetzen).

Рассматривая причины такой метафоризации, можно прийти к выводу о том, что сама система языка способствует семантическому сдвигу. Семантические сдвиги в представленных структурах предложений являются следствием грамматического отношения между подлежащим и сказуемым, придающим речевому акту форму предложения. Отношение подлежащее-сказуемое относится к языковым универсалиям и остается неизменным в своем грамматическом значении. Грамматическое подлежащее характеризуется грамматическим сказуемым. Языковая абстракция в позиции подлежащего благоприятствует метафорическому сдвигу глагольного значения.

Выше приведенный анализ подтверждает тезис о том, что между лексическим и грамматическим значением существуют сложные и разнообразные отношения - и все это при доминировании грамматического значения. Подтверждено, что предложение в языковом сознании человека и соответственно в его речевой деятельности существует лишь как грамматическая структура. Одновременно взаимоотношения лексического и грамматического значения являются основой почти неограниченной возможности выражений, как в языке, так и с помощью языка.

$$
* * *
$$

1. Арутюнова, Н. Д. Метафора и дискурс / Н. Д. Арутюнова // Теория метафоры. - Москва : Прогресс, 1990. - С. 5-33.

2. В Виноградов, В. В. Русский язык / В. В. Виноградов. - Москва : Высшая школа, 1972.

3. Кацнельсон, С. Д. Типология языка и языковое мышление / С. Д. Кацнельсон. - Москва : URSS, 2009. - Изд. 4-е.

\section{Самаева А.М. \\ Основные характеристики понятия «концепт» В современной лингвокультурологии}

Калмыцикий государственный университет (Россия, Элиста)

doi: 10.18411/lj-05-2021-280

\section{Аннотация}

В данной статье рассматриваются характерные обозначения понятия «концепт» с точки зрения лингвокультурологии. Разнообразие подходов изучения данного термина дает более широкий обзор на картину его семантики.

Ключевые слова: концепт, понятие, язык, культура, лингвистика, лингвокультурология. 